EPiC Series in Engineering
Volume 3, 2018, Pages 659-667
HIC 2018. 13th International
Conference on Hydroinformatics

\title{
The Nile System Dynamics Model for Water- Food-Energy Nexus Assessment
}

\author{
Hamdy Elsayed ${ }^{1,2}$, Slobodan Djordjevic ${ }^{1}$, and Dragan Savic ${ }^{1}$ \\ ${ }^{1}$ Centre for Water Systems, College of Engineering, Mathematics and Physical Sciences, \\ University of Exeter, Exeter, Devon EX4 4QF, UK \\ ${ }^{2}$ Civil Engineering Department, Faculty of Engineering Shebin Elkom, Menoufia University, \\ Shebin Elkom, Menoufia, Egypt \\ Ha 351 dexeter.ac.uk, S.Djordjevic@exeter.ac.uk, D.Savic@exeter.ac.uk
}

\begin{abstract}
The Nile River is considered one of the most complex rivers in the world because of its transboundary nature and its significance for riparian countries. Currently, the basin experiences challenges stemming from a rapid population increase and the prospect of a significant economic growth, which in turn have sparked development plans aimed at meeting the growing demand for water, energy, and food. A System Dynamics approach provides a unique framework to integrate the physical system and the socio-economic drivers with the ability to capture the interaction and feedback processes between different system components. A water resources model for the entire Nile basin using the System Dynamics approach was developed as a first step. The model results for the flows at gauge locations showed a good agreement with the historical flows measurements, which reflects the SDM ability to capture the dynamic behaviour of the river and reproduce the patterns and trends of the historical flows. A description of the model development process is presented along with simulation results at the key hydrological sites in the basin. The potential to integrate the developed model with food, energy and socio-economic drivers in the basin is provided.
\end{abstract}

\section{Introduction}

The River Nile is considered the longest river in the world with a length of about $6,700 \mathrm{~km}$. The basin spreads across 11 countries (Tanzania, Uganda, Rwanda, Burundi, Congo (Kinshasa), Kenya, Ethiopia, Eretria, South Sudan, Sudan and Egypt). It is considered one of the most complex rivers in the world because of its transboundary nature, i.e., its size, a variety of climates and topographies, and the high system losses. However, the mean annual flow of the river is relatively low compared to the 
major world rivers $\left(84 \times 10^{9} \mathrm{~m}^{3}\right)$. The Nile originates from two main tributaries; the White Nile, and the Blue Nile, Figure 1. The White Nile originates from the Equatorial Lakes, which are contributing annually about $8 \times 10^{9} \mathrm{~m}^{3}$. The water losses by evaporation and transpiration are high in the Sudd region and are estimated to be approximately half of the Sudd inflows. The average annual inflow of the White Nile at Malakal (downstream of the Sobat-White Nile confluence) is $28.50 \times 10^{9}$ $\mathrm{m}^{3}$. While the Blue Nile originates from Lake Tana and contributes to about $60 \%$ of the total annual flow of the main Nile. Inside Sudan, the Blue Nile receives water from two major tributaries, the Dinder and the Rahad. The long-term mean annual discharge at the Sudanese-Ethiopian borders is estimated at $48.66 \times 10^{9} \mathrm{~m}^{3}$ [2]. The river continues running further downstream through arid and hyper-arid regions until reaches Lake Nasser at Wadi Halfa. The water is released from Lake Nasser, through Aswan High Dam, to meet the different downstream water demands in Egypt [2-4]. In order to provide a buffer to the climatic and hydrologic variability, large infrastructures were constructed in Egypt and Sudan. Future developments across the basin are planned to meet the growing demand for water, food and energy due to rapid population increase and economic growth [5].

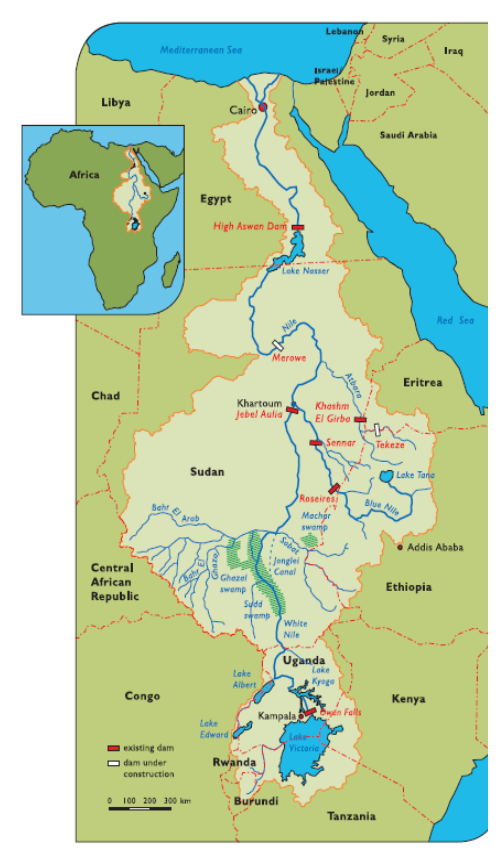

Figure 1 The Nile basin, [1]

\section{Material and methods}

System Dynamics Modelling (SDM) is based on nonlinear dynamics theory and feedback control. It is a general modelling approach and can be applied to any dynamic system at various temporal and spatial scales [6]. SDM starts with a qualitative conceptual model in which the main interactions among the system components are defined qualitatively in form of causal loop diagrams (CLDs). CLDs are composed of variables connected by arrows and positive/negative signs, which represent the causal relationships between the system variables. Positive causal relationship (reinforcing) means that a decrease/increase in variable (A) would result in a decrease/increase in variable (B), i.e., the change in the same direction. While negative causal relationship (balancing) means that a decrease/increase in variable (A) would lead to an increase/decrease in variable (B), i.e., the change is in the opposite direction. The combination of positive and negative relationships might form feedback loops, [7]. There are two types of feedback loops; (a) reinforcing feedback loop, and (b) balancing feedback loop. A reinforcing feedback loop is characterized by the continuation of growth or decline within the system state, while a balancing loop tries to reduce the difference between the current system state and the desired state. CLDs are then quantified by stock and flow diagrams (SFDs). It could be considered that CLDs emphasize the feedback of the system while the SFDs emphasizes the underlying mathematical relationships, [8]. System Dynamics (SD) components are: (a) Stocks, which represent anything that accumulates (e.g., reservoir), (b) Flows, which are activities that fill or deplete stocks (e.g., inflow and outflow), (c) Connectors, which link model elements and transfer information among model elements, and (d) Convertors, which include arithmetic operations that can be performed on flows and logical functions that operate the system (e.g., operating rules for a reservoir).

Several SDM studies have been conducted in the area of water resources management including regional analysis and river basin planning, urban water, flooding, and reservoir operation studies [9]. 
Aboelata [10] developed a framework for modelling a water resources policy and applied it to the main Nile in Egypt. Xu et al. [11] analysed the sustainability of water resources in the Yellow River, China, using SDM under different supply and demand scenarios and climate change. Madani and Mariño [12] addressed the water management problem in the Zayandeh-Rud watershed, Iran, by applying an SDM while considering the socio-economic-political features in the region. SDM was used to integrate the surface water and groundwater with policy and management criteria in the Bear River basin, Idaho, Utah and Wyoming [13]. Kotir, et al. [14] studied the interaction between the population, water resources and the agriculture production in the Volta River basin, Ghana. Other case studies are available from (Zarghami et al. [15], Dai et al. [16], Sušnik, et al. [17], Tidwell, et al. [18], and Qin et al. [19]). These SDM applications provided better understanding of the dynamic behaviour of river basins. However, most of these studies considered the basin as spatially aggregated, which ignores administrative boundaries and constraints and the management of water infrastructure elements. Furthermore, although the basin hydrology and socio-economic related water activities (e.g., agriculture and domestic demands) were normally included and quantified, the interlinkages among socioeconomic, water, energy and food sectors in the area were not addressed. Therefore, an SD model that captures the dynamic behaviour of the Nile basin while considering the administrative constraints and water management infrastructures across the basin is developed and described below. The developed model will be integrated with food, energy, and socio-economic drivers to: (a) better understand the broader interdependency and feedbacks within complex human-environmental systems, (b) evaluate the socio-economic impact and policy options in different sectors on the water, energy and food nexus in the Nile basin in the future.

\subsection{Model development}

A water balance model for the entire Nile basin was developed to simulate the key hydrological features and different activities that affect the surface water availability (e.g., water withdrawals) and management of water infrastructure (e.g., dams and diversions). To construct the model, two generic structures were considered: (a) river reach, and (b) reservoir [13]. The former captures the flows within a given reach and includes runoff from different tributaries, upstream inflows, different water abstractions, losses in the reach (e.g. seepage), and return flows. The latter structure considers the upstream inflows, evaporation, rainfall rates in a reservoir, reservoir operation rules, and releases from the reservoir. The CLDs of the two generic structures was developed firstly using Vensim [20] to illustrate the cause and effect relationship between the system elements as shown in Figure 2. For example, the increase in the evaporation and water released from a reservoir reduce the stored volume (negative relationship), while the increase in upstream inflows and precipitation over the reservoir surface increase the stored volume (positive relationship). After that, the proposed CLDs are quantified through SFDs, as shown in Figure 3. The rectangles denote stocks which represent water storage in reservoirs and lakes. The stocks are connected by lines with valves, which represent the water inflows and outflows from a reservoir. The other variables are convertors that control the inflows, outflows and stocks. The wetlands across the basin like Sudd and Machar Marshes, in Figure 1, are modelled as single reservoirs where evaporation, precipitation, and flooding processes are represented by a Surface area_Elevation_Storage relationship.

The entire model was developed by linking the river reach/reservoir to the relevant elements sequentially until the whole basin, its hydrology and water management and abstraction activities were represented. The complete simulation model was implemented in the Simile environment [21]. Simile is primarily developed for environmental studies based on an SD paradigm. . The model is divided into three main sub-models: The White Nile sub-model, the Blue Nile Sub-model, and the main Nile in Egypt. Each sub-model is composed of interlinked sub-model groups, which is an SDM feature that enables dividing a complex system into smaller subsystems. A simplified layout for the Nile water 

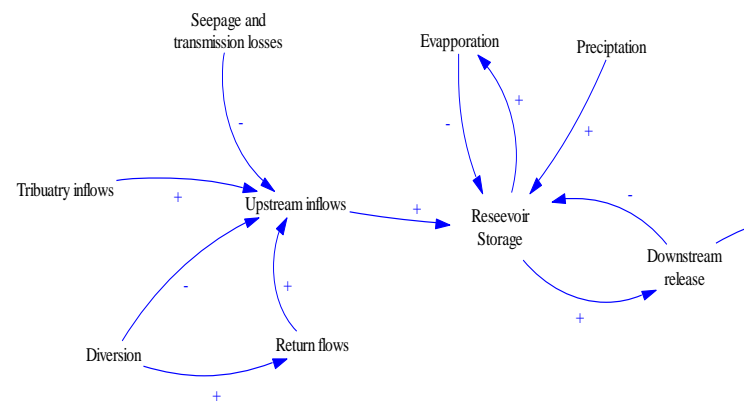

Figure 2 CLDs of the river reach and reservoir

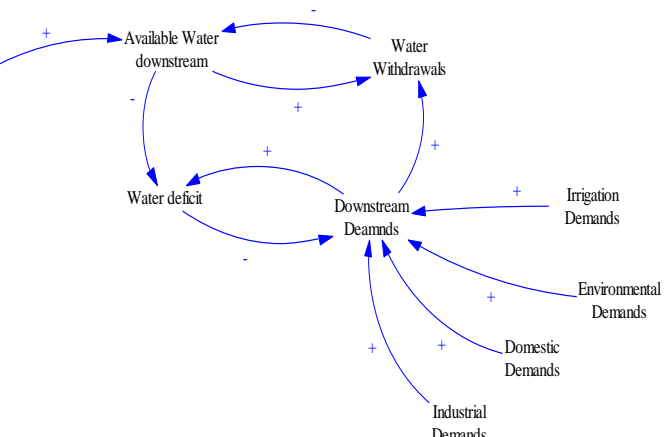

Demands



Figure 3 The combination of the river reach and reservoir structure, adapted from Sehlke and Jacobson [13]

resources system representing the main tributaries and the main reservoirs in Simile environment is shown in Figure 4.

The model defines a set of differential equations that have to be solved by numerical integration methods available in Simile. The developed model is a part of an ongoing work where SDM was chosen for: (a) its ability to integrate the biophysical and socio-economic systems into one model without the need for separate software packages; (b) providing understanding of how complex systems evolve and change over time by making available a dynamic view of the system; (c) its ability to divide a complex system into many sub-models; and (d) its capacity to handle the feedback process between the system components. These advantages of SDM favour Simile over conventional modelling approaches. 
The storage in a reservoir can be mathematically represented by a mass balance equation as follows:

$\mathrm{S}_{\mathrm{t}+1}=\mathrm{S}_{\mathrm{t}}+\mathrm{I}_{\mathrm{t}}+\mathrm{P}_{\mathrm{t}}-\mathrm{O}_{\mathrm{t}}-\mathrm{E}_{\mathrm{t}}-\mathrm{SP}_{\mathrm{t}}$

Where;

$\mathrm{S}_{\mathrm{t}+1}$ : Storage in reservoir at time $(\mathrm{t}+1)$

$\mathrm{S}_{\mathrm{t}}$ : Storage in reservoir at time $(\mathrm{t})$

$\mathrm{I}_{\mathrm{t}}$ : Reservoir Inflow at time $(\mathrm{t})$

$\mathrm{P}_{\mathrm{t}}$ :Precipitation over the reservoir at time $(\mathrm{t})$

$\mathrm{O}_{\mathrm{t}}$ : Reservoir outflow at time $(\mathrm{t})$

$\mathrm{E}_{\mathrm{t}}$ : Reservoir evaporation at time $(\mathrm{t})$

$\mathrm{SP}_{\mathrm{t}}$ : Spill from reservoir at time $(\mathrm{t})$

The reservoir inflows include the upstream tributaries inflows, modelled upstream water flows, and return flows from upstream diversions. The precipitation/evaporation from a reservoir was calculated by the product of the rainfall/evaporation rate and the surface area for each reservoir at each time step. The Surfacearea_Elevation_Storage relationship was used to estimate the surface area for the reservoir at each time step.

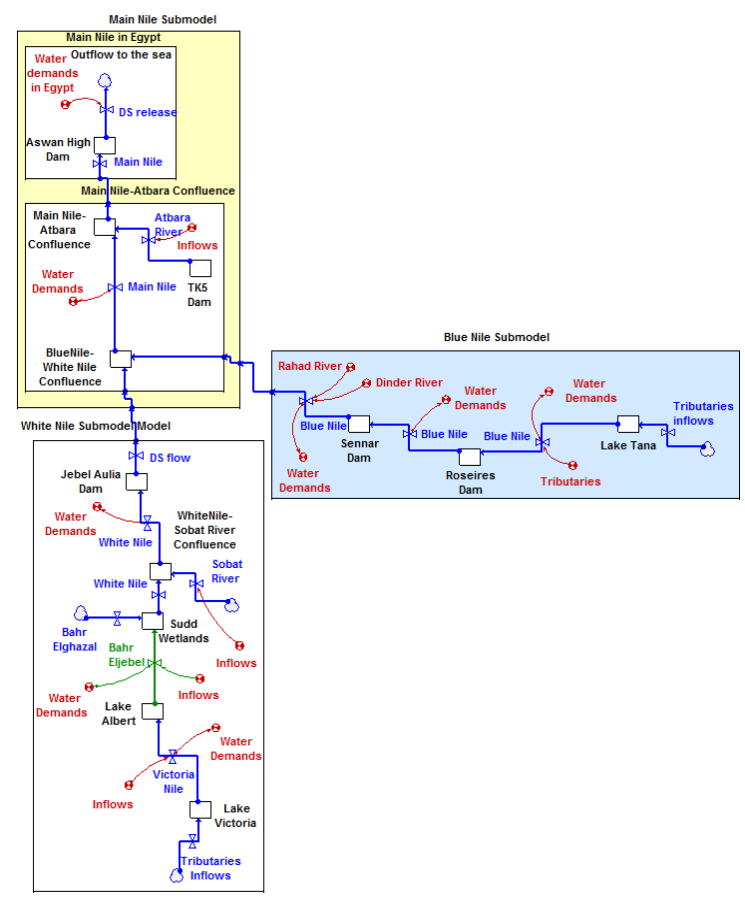

Figure 4 Simplified layout for the Nile water resources in Simile

The outflow from a reservoir is determined by its operation rules and can be subjected to the general conditions;

$$
\mathrm{O}_{\mathrm{t}}=\left\{\begin{array}{lll}
\text { Downstream demands } & \text { if } & \left(\mathrm{S}_{\mathrm{t}}-\mathrm{S}_{\mathrm{d}}\right) \geq \text { Downstream demands } \\
\left(\mathrm{S}_{\mathrm{t}}-\mathrm{S}_{\mathrm{d}}\right) & \text { if } & \left(\mathrm{S}_{\mathrm{t}}-\mathrm{S}_{\mathrm{d}}\right)<\text { Downstream demands }>0 \\
0 & \text { if } & \mathrm{S}_{\mathrm{t}}>\mathrm{S}_{\mathrm{d}}
\end{array}\right.
$$

Where; $S_{d}$ is the reservoir dead storage.

The prioritized operation rules for single and multipurpose dams through the year were written using conditional statements (IF-THEN-ELSE). The hydropower flows were estimated iteratively, normally 3 or 4 iterations were needed to determine the actual flows with acceptable accuracy.

The spill from reservoir is calculated based on its maximum storage capacity:

$$
\mathrm{SP}_{\mathrm{t}}=\left\{\begin{array}{lll}
\left(\mathrm{S}_{\mathrm{t}}+\mathrm{I}_{\mathrm{t}}+\mathrm{P}_{\mathrm{t}}-\mathrm{E}_{\mathrm{t}}-\mathrm{S}_{\max }\right) & \text { if } & \left(\mathrm{S}_{\mathrm{t}}+\mathrm{I}_{\mathrm{t}}+\mathrm{P}_{\mathrm{t}}-\mathrm{E}_{\mathrm{t}}-\mathrm{S}_{\max }\right)>0 \\
0 & \text { if } & \left(\mathrm{S}_{\mathrm{t}}+\mathrm{I}_{\mathrm{t}}+\mathrm{P}_{\mathrm{t}}-\mathrm{E}_{\mathrm{t}}-\mathrm{S}_{\max }\right) \leq 0
\end{array}\right.
$$

Where $S_{\max }$ is the maximum reservoir storage. 


\section{Data requirement}

The available basin-wide hydrologic input for the period (1950-2014) was derived from MIKE HYDRO BASIN model that is linked to the Nile Basin Decision Support System (NB-DSS), [22]. Current and historical irrigation abstractions and diversions across the basin, seepage losses at different reaches, time delays were also obtained from NB DSS. The Initial storage volumes, Surface area_Elevation_Storage relationships, rainfall and evaporation rates, storage zones, operation rules for reservoirs, lakes and assumed reservoirs (representing wetlands), the prioritised operation rules and the installed hydropower capacity, hydropower demands, and operating head of the hydropower plants were obtained from a number of sources $[22,23]$. The actual starting operation date of the reservoirs was derived from Wheeler et al. [23] and embedded into the simulation. Different water uses in Egypt were obtained from available published data from Central Agency for Public Mobilization and Statistics (CAPMAS), [24].

\section{Model simulation results}

After implementing the model as described above and preparing the input data for the model, the simulation is started. The model runs for 768 time steps at a monthly resolution, starting from the year 1950. The model can be used to estimate the flow at any point across the basin, reservoir levels, storage, releases and water diversions and withdrawals at any particular time. The software allows for visualization of the simulation results using tables and graphs. The modelled flows are calibrated: (1) by comparing the historical flows at gauges, dam releases, and water diversions with the simulated flows from the model, and (2) according to the performance rating criteria provided by Moriasi et.al [25]. Table 1 displays the calibration period, root mean square error-observation standard deviation ratio (RSR), Nash-Sutcliffe efficiency (NSE), percent bias (PBIAS) and the overall performance ratings for the flows at each gauge location. Figures 5, 6 show a sample of the simulation results for the flow at El Deim station (just upstream of the El Roseires Dam) on the Blue Nile and at Malakal on the White Nile, (Figure 1), where values are given in million $\mathrm{m}^{3}$. The simulated flows at these locations showed a good to very good performance based on their statistical results as shown in Table 1. Graphically, there is a clear agreement between the modelled and historical flows, and the high and low flows are synchronized with the historical measured flows, which reflects the SDM ability to capture the dynamic behaviour of the river. The model could not capture the high flows events like the one occurred during 1960s, as shown in Figure 6, due to the increased outflows from Lake Victoria when the high rainfall over the lake was observed [3]. This is because the simplifying assumptions were used for representing the complex Sudd wetlands as single reservoirs with empirical Surface area_Elevation_Storage relationships to estimate evaporation, precipitation and flooding. This could be improved by better representation of the Sudd wetlands through more refined Surface area_Elevation_Storage relationships and considering the wetlands as sinks where the water is lost from the system (not as a reservoir where water is stored) [26]. Further improvements can be achieved by using the historical records for catchments outflows as model inputs when available. 
Table 1 Flows' calibration results at the main gauge stations

\begin{tabular}{lccccc}
\hline Location & $\begin{array}{c}\text { Calibration } \\
\text { period }\end{array}$ & RSR & NSE & PBIAS & $\begin{array}{c}\text { Performance rating, } \\
{[25]}\end{array}$ \\
\hline Lake Victoria at Jinga & $(1950-1970)$ & 0.22 & 0.95 & -1.23 & Very good \\
\hline Bahr ElJebel at Mongalla & $(1950-1983)$ & 0.47 & 0.78 & -3.98 & Very good \\
\hline White Nile at Malkal & $(1950-2002)$ & 0.55 & 0.69 & 1.50 & $\begin{array}{c}\text { RSR and NSE (good), } \\
\text { and PBIAS (very good) }\end{array}$ \\
\hline Sobat at Hill Doleib & $(1950-2002)$ & 0.53 & 0.72 & 7.73 & $\begin{array}{c}\text { RSR and NSE (good), } \\
\text { and PBIAS (very good) }\end{array}$ \\
\hline Baro at Gambella & $(1950-1959)$ & 0.46 & 0.78 & 4.88 & Very good \\
\hline $\begin{array}{l}\text { Blue Nile at Khartoum } \\
\text { and Soba }\end{array}$ & $(1950-1997)$ & 0.52 & 0.73 & 2.81 & $\begin{array}{c}\text { RSR and NSE (good), } \\
\text { and PBIAS (very good) }\end{array}$ \\
\hline Blue Nile at Deim & $(1950-1997)$ & 0.30 & 0.91 & -0.28 & Very good \\
\hline Main Nile at Tamaniat & $(1950-1997)$ & 0.53 & 0.71 & 10.43 & Good \\
\hline
\end{tabular}

Note desired values: RSR $<0.50$, NSE $>0.75$ and PBIAS $< \pm 10$

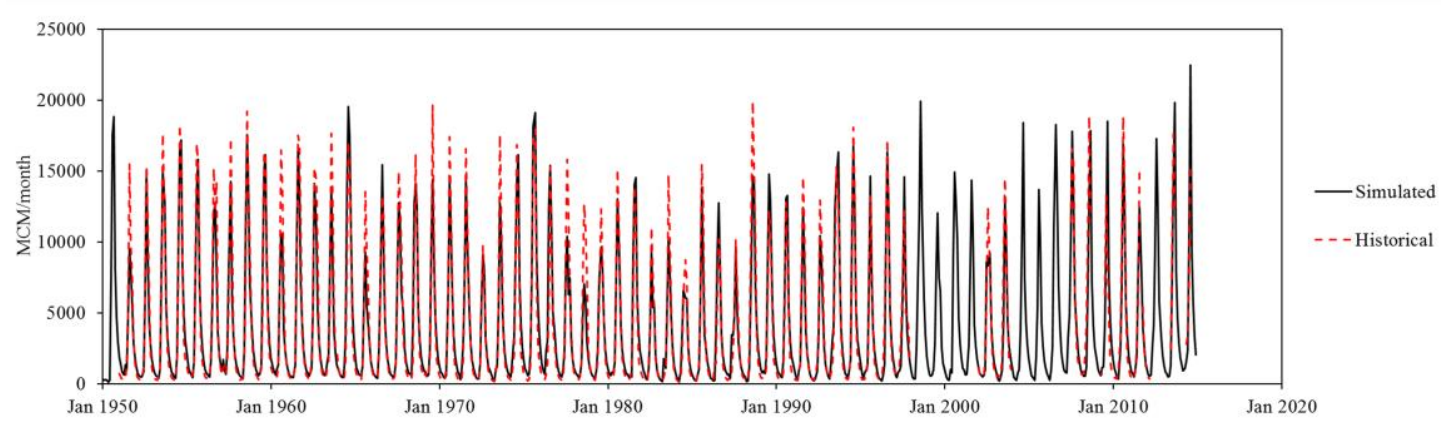

Figure 5 Historical and simulated flow at El Deim gauge station

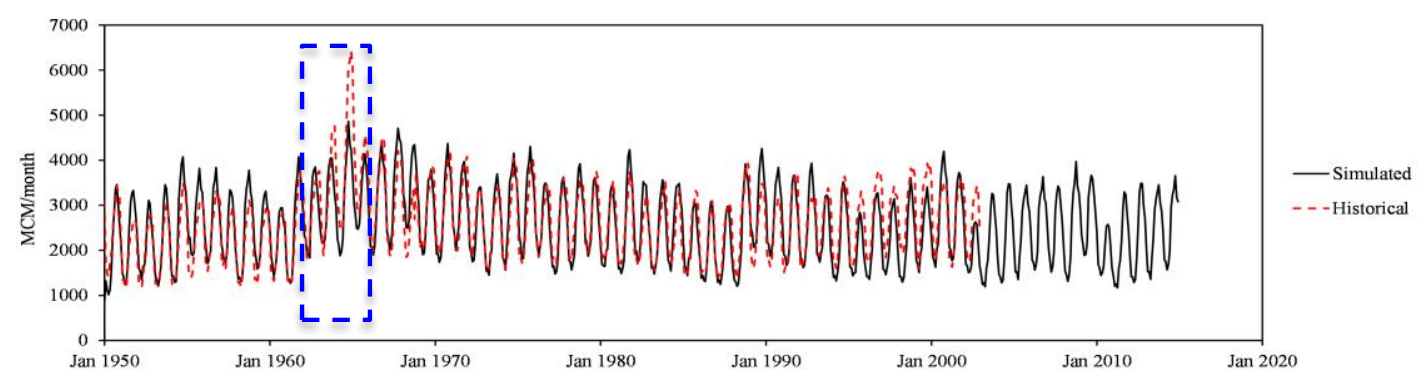

Figure 6 Historical and simulated flow at Malakal gauge station

\section{Conclusions}

The main aim of the presented work is to develop a water balance model for the entire Nile basin which captures the dynamic behaviour of the river and addresses the management of water infrastructure using SDM. SDM demonstrated its capability as an efficient technique for implementing and simulating a complex water resource system, such as the entire Nile basin. The regional 
hydrological model developed in Simile, with the best available data, showed satisfactory performance ratings based on the statistics of the modelled flows at the gauge locations as shown above in Table 1 . The model performance ratings for the flows at the main gauge stations ranged from good to very good in terms of trends (NSE), residual variation (RSR), and average magnitude (PBIAS). The model calibrations results indicated that the model was able to reproduce the dynamic behaviour of the Nile and the management of water infrastructure across the basin. The regional model showed a satisfactory performance and is fit for the purpose for which it is developed. The developed model will be integrated with socio-economic, food, and energy data in the basin to provide better understanding of the dynamic behaviour of the system and evaluate different policy scenarios and their impacts on the system. In order to use the developed model, uncertainty analysis for the model predictions (e.g., model structure, model parameter values) is required as suggested by Beven and Binley [27] and this will be investigated in future work.

\section{Future Work}

SDM provides a unique framework for incorporating the biophysical system with the socioeconomic sectors with no need for additional software packages. This feature will be exploited in the future to integrate the developed water resources model with food, energy, population and economic sectors in the basin. The integrated model will be used to capture the feedback process and the interaction between the physical system and socio-economic drivers in the basin. Moreover, it will be used to assess the impacts of: various policy options, management scenarios in different sub-sectors, and the socio-economic developments in the Water Energy Food Nexus in the Nile Basin in the short and long term. A number of cooperation opportunities will also be explored, for example, a regional energy trade from the basin hydropower potential would offer an opportunity to meet the increasing energy demand in the riparian countries. Moving the intensive water use crops in arid and semi-arid areas to sub-humid areas along with achieving their potential yield is another opportunity for cooperation and for improving the socio-economic conditions in the basin.

\section{Acknowledgements}

The first author would like to express his gratitude to the Ministry of Higher Education (MoHE), Egypt and College of Engineering, Mathematics and Physical Sciences, University of Exeter, UK for the financial support for this research (PhD Scholarship) and to the University of Exeter for providing the tools and facilities to execute this work, and also to DHI group for providing free licenses of MIKE HYDRO BASIN and MIKE HYDRO RIVER.

\section{References}

[1] MWRI, Integrated Water Resources Management Plan, Ministry of Water Resources and Irrigation: Egypt, 2005

[2] J. V. Sutcliffe, Y. P. Parks, The hydrology of the Nile, No. 5. Wallingford, Oxfordshire, UK: International Association of Hydrological Sciences, 1999.

[3] P. P. Howell, and J. A. Allan, eds., The Nile: Sharing a Scarce Resource: A Historical and Technical Review of Water Management and of Economical and Legal Issues, Cambridge University Press, 1994. 
[4] M. M. Shahin, Hydrology of the Nile basin, Vol. 21. Elsevier, 1985.

[5] S. B. Awulachew, eds., The Nile River Basin: water, agriculture, governance and livelihoods, Routledge, 2012

[6] J.D. Sterman, Business dynamics: systems thinking and modeling for a complex world, No. HD30. 2 S7835 2000. 2000.

[7] Mirchi, A., et al., Synthesis of system dynamics tools for holistic conceptualization of water resources problems. Water resources management, 2012. 26(9): p. 2421-2442.

[8] Zhuang, Y., A system dynamics approach to integrated water and energy resources management, in Department of Civil and Environmental Engineering, College of Engineering. 2014, University of South Florida.

[9] I. Winz, G. Brierley, and S. Trowsdale, The use of system dynamics simulation in water resources management, Water resources management 23.7 (2009) 1301-1323.

[10] M. Aboelata, Object-oriented modelling framework for water resources policy analysis, M.sc thesis, in Department of Civil and Geological Engineering, University of Manitoba: Manitoba, (1998).

[11] Z. X. Xu, et al, Sustainability analysis for Yellow River water resources using the system dynamics approach, Water Resources Management 16.3 (2002) 239-261.

[12] K. Madani,, and M. A. Mariño, System dynamics analysis for managing Iran's Zayandeh-Rud river basin, Water resources management 23.11 (2009) 2163-2187.

[13] G. Sehlke, J. Jacobson. System dynamics modeling of transboundary systems: the Bear River basin model, Groundwater 43.5 (2005) 722-730.

[14] J. H. Kotir, et al., A system dynamics simulation model for sustainable water resources management and agricultural development in the Volta River Basin, Ghana, Science of the Total Environment 573 (2016) 444-457.

[15] M. Zarghami, M. R., Fotookian, N. Safari, A. Aslanzadeh, Reservoir operation using system dynamics under climate change impacts: a case study of Yamchi reservoir, Iran. Arabian Journal of Geosciences, 9.16 (2016) 678.

[16] S. Dai, L. Li, H. Xu, X. Pan, X. LiA system dynamics approach for water resources policy analysis in arid land: a model for Manas River Basin. Journal of Arid Land, 5.1 (2013) 118-131.

[17] J. Sušnik, L. Vamvakeridou-Lyroudia, D. Savić, Z. Kapelan, Integrated modelling of a coupled water-agricultural system using system dynamics. Journal of Water and Climate Change, 4.3 (2013) 209-231.

[18] V.C. Tidwell, H. D. Passell, S. H. Conrad, R. P. Thomas, System dynamics modeling for community-based water planning: Application to the Middle Rio Grande. Aquatic SciencesResearch Across Boundaries, 66.4 (2004) 357-372.

[19] H. P. Qin, Q. Su, S. T. Khu, An integrated model for water management in a rapidly urbanizing catchment. Environmental modelling \& software, 26.12 (2011) 1502-1514.

[20] Vensim. "Vensim Simulation Software." (2018). Available from: http://vensim.com/.

[21] Simulistics and Ltd. 2017; Available from: http://www.simulistics.com/.

[22] NBI, Nile Basin Decision Support System, Nile Basin Initiative: Entebbe, Uganda, 2016,

[23] K. G., Wheeler et al., Cooperative filling approaches for the grand Ethiopian renaissance dam, Water International 41.4 (2016): 611-634.

[24] CAPMS. Central Agency for Public Mobilization and Statistics: Available from: http://www.capmas.gov.eg/.

[25] D. N. Moriasi, J. G. Arnold, M. W. Van Liew, R. L. Bingner, R. D. Harmel, T. L. Veith, Model evaluation guidelines for systematic quantification of accuracy in watershed simulations. Transactions of the ASABE, 50(3), (2007) 885-900.

[26] F. Newhouse, problem of the upper Nile. Ministry of public works, Cairo, 1929.

[27] K. Beven, A. Binley, The future of distributed models: model calibration and uncertainty prediction. Hydrological processes, 6(3), (1992) 279-298. 